\title{
Visio mystica im Spannungsfeld frühchristlicher Überlieferungen
}

Die Lehre der sogenannten Antoniusbriefe von der Gottes- und Engelschau und das Problem unterschiedlicher spiritueller Traditionen im frühen ägyptischen Mönchtum

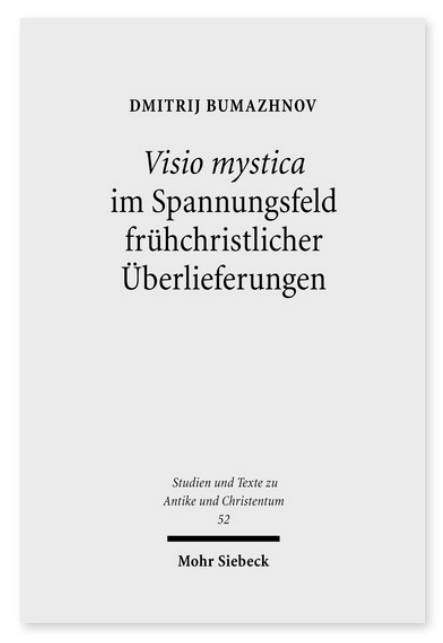

2009. XII, 308 Seiten. STAC 52

ISBN 978-3-16-151351-0

DOI 10.1628/978-3-16-151351-0

eBook PDF 104,00€

ISBN 978-3-16-149729-2

fadengeheftete Broschur 104,00€
Dmitrij Bumazhnov widmet sich dem Problem der spirituellen Traditionen im frühen ägyptischen Mönchtum. Am Beispiel der visio mystica in den sog. Antoniusbriefen, in der pachomianischen Tradition, in den Apophthegmata patrum, bei dem hl. Johannes Cassian, in den Briefen des hl. Ammonas, im Traktat De patientia des Ps.-Ammonas und in den Schriften des hl. Epiphanius von Salamis demonstriert er, dass das ägyptische Mönchtum im 4. Jh. zwei unabhängige und miteinander konkurrierende Traditionen der mystischen Schau - die unmittelbare Augenschau und die mentale Gottesschau - kannte, die sich auf die biblische und parabiblische Überlieferung einerseits und auf die christlich-platonische Tradition andererseits zurückführen lassen. Strittig dabei ist die Frage, ob man die Gottheit mit bloßen Augen betrachten kann. Das Bestehen der beiden mönchisch-ägyptischen Traditionen weist der Autor für die Zeit gegen 370 nach, womit er eine Vorstufe des ersten origenistischen Streites 399 in Ägypten dokumentiert. Das Auseinanderhalten der beiden Traditionen liefert einen wichtigen Ansatzpunkt für das Studium der weitgehend unbekannten Anfänge des Mönchtums im Niltal. Die Analyse der Briefe des sog. Antoniuskorpus zeigt außerdem, dass der erste Brief und die Briefe 2-7 auf unterschiedliche Autoren zurückgehen, wobei der Brief 1 mit größerer Wahrscheinlichkeit dem Vater der Mönche zugeschrieben werden kann als der Rest der Sammlung. In Bezug auf das Traktat De patientia des Ps.-Ammonas wird deutlich, dass dieser Text im späten 4. Jh. in den origenistischen mönchischen Kreisen Ägyptens entstanden ist.

Dmitrij Bumazhnov Geboren 1967; Studium der Klassischen Philologie an der Universität St. Petersburg; 2001 Promotion in »Sprachen und Kulturen des Christlichen Orients« Tübingen; 2008 Habilitation für das gleiche Fach in Tübingen; seit 2011 Mitglied des Forschungszentrums EDRIS, Göttingen.

Jetzt bestellen:

https://mohrsiebeck.com/buch/visio-mystica-im-spannungsfeld-fruehchristlicher-ueberlieferungen-9783161513510? no_cache=1

order@mohrsiebeck.com

Telefon: +49 (0)7071-923-17

Telefax: $+49(0) 7071-51104$ 